\title{
FERROCARRIL Y MERCADO DE TIERRAS. FUGAZ EXPECTATIVA INMOBILIARIA PARA EL SUROESTE DE LA CIUDAD DE SANTA FE (ARGENTINA)
}

\section{María Alejandra Saus}

Arquitecta. Becaria del Consejo Nacional de Investigaciones Científicas y Técnicas CONICET. Miembro Titular del Instituto de Teoría e Historia Urbano - Arquitectónica INTHUAR. Ayudante de cátedra ordinaria en la Facultad de Arquitectura, Diseño y Urbanismo; Universidad Nacional del Litoral FADU-UNL. Asistente en Investigación del Curso de Acción para la Investigación y Desarrollo CAI+D, programa: "Infraestructura Ferroviaria en Santa Fe. Modernización Arquitectónica y Construcción Urbana del Espacio Público", Secretaría de Ciencia y Técnica, UNL.

ISNN 1666-6I86. Volumen I3 No I3 (Octubre 20I2) pp. 027-046 - Recibido: 06-0I-I2 Aprobado: I5-09-12 


\section{Resumen}

Los ferrocarriles han sido históricamente considerados promotores de nueva centralidad urbana, y las compañías ferroviarias, usualmente vinculadas con exitosos emprendimientos inmobiliarios en torno a su infraestructura. Sin embargo, el examen del caso de Santa Fe, enfocado en una de sus tres estaciones localizada en el borde suroeste, evidencia cómo otras variables de la historia del ferrocarril y la ciudad debilitan esas afirmaciones. En este sentido, el artículo demuestra que las expectativas originarias del mercado de tierras se desvanecieron en unas décadas, y quedó confirmada la periferia urbana.

Palabras clave

Ferrocarril, mercado de tierras, cambios de uso.

\section{$\underline{\text { Abstract }}$}

Railways have historically been considered the promoters of the new urban centrality, and railway companies have usually been associated with successful real-estate businesses centered on their infrastructure. However, the analysis of the Santa Fe railway, focused on one of its three stations located on the south-west periphery shows how other indicators of the railway and city history weaken the above assumptions. In this sense, this article shows that the original demand of the land market disappears after a few decades, thus confirming an urban periphery result.

Key words

Railway - Land Market - Land Use Changes 
Ferrocarril y mercado de tierras. Fugaz expectativa inmobiliaria para el suroeste de la ciudad de Santa Fe (Argentina)

\section{INTRODUCCIÓN}

A principios del siglo XX la ciudad de Santa Fe poseía tres estaciones ferroviarias: la terminal de los ferrocarriles de la provincia de Santa Fe, inaugurada en 1885 y localizada junto al área central de la ciudad $(\mathrm{FCSF})^{1}$; la estación del ferrocarril británico Buenos Aires y Rosario, librada al servicio en 1892 en el sector suroeste (FCBAyR) ${ }^{2}$, y la terminal estatal de la línea Central Norte Argentino, proyectada y construida entre 1912 y 1928 , emplazada en el límite nordeste que poseía la planta urbana por entonces (FCCNA) ${ }^{3}$. En este trabajo abordamos como unidad de análisis el segundo ferrocarril y el entorno urbano inmediato de su estación, puesto que este manifiesta una serie de efectos espaciales e históricos que ofrecen una sustanciosa caracterización al sector urbano y ferroviario al que hacemos referencia.

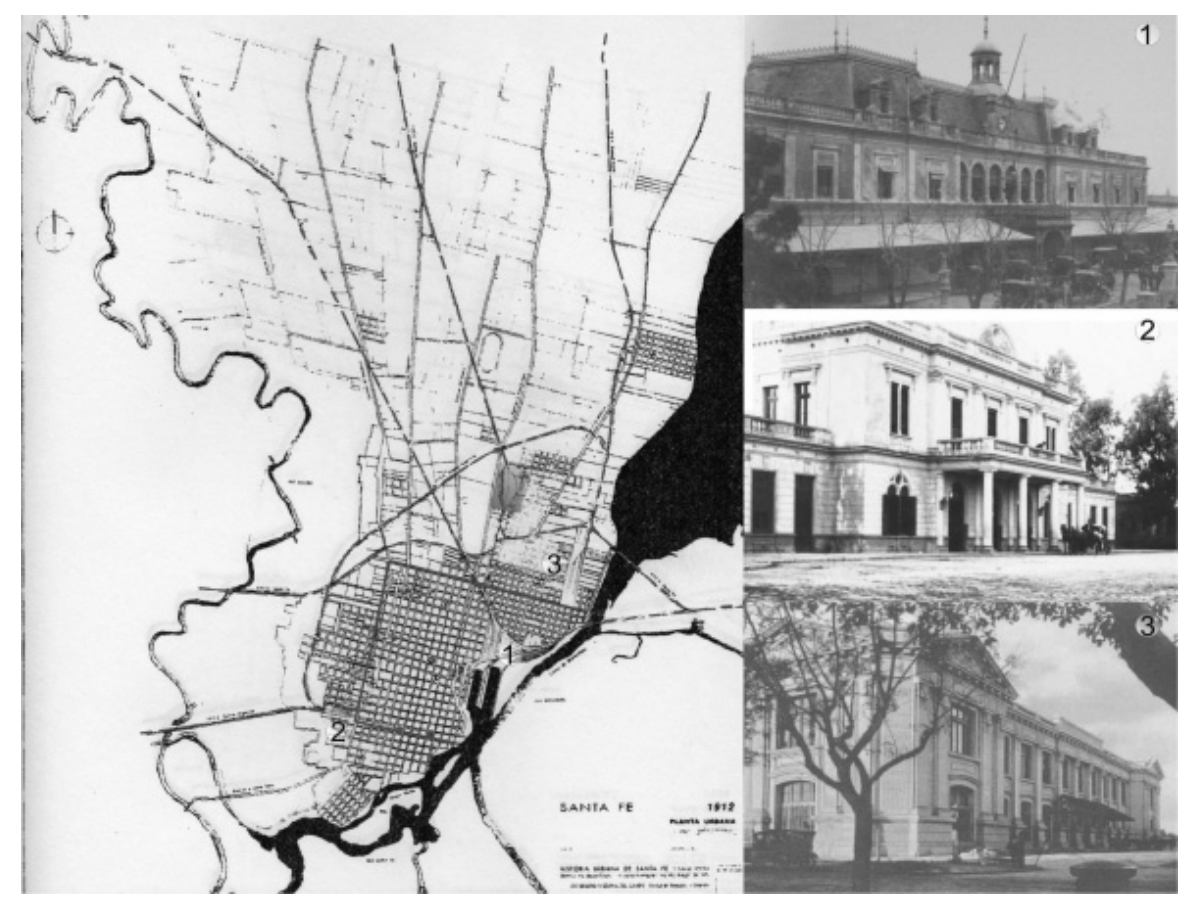

1- Ferrocarril Santa Fe a las Colonias, 1885. En 1889 el gobierno provincial lo arrengobierno provincial lo arren-
dó a Fives Lille, que transfirió el contrato a la Compañía Francesa de Ferrocarriles de Santa Fe (FCSF). En 1900 el gobierno le otorgó la propiedad. Fue absorbido poropiedad. Fue absorbido por el Ferrocarril Nacional General Manuel Belgrano (FCNGMB) con la nacionalización de 1947. Se encontraba sobre las actuales calles Belgrano e Hipólito Yrigoyen.

2- El Ferrocarril Buenos Aires y Rosario (FCBAyR), que inauguró su estación en el sector suroeste de la ciudad de Santa Fe en el año 1891. era de capitales británicos y se fusionó en 1902 con el Ferrocarril Central Argentino (FCCA), también británico. Fue nacionalizado en 1948 con el nombre de Ferrocarril Nacional General Bartolomé Mitre (FCNGBM) y su edificio Mitre (FCNGBM) y su edificio
aún se encuentra en Gral. López y Dr. Zavalla.

Localización de las estaciones. 1 FCSF 2-FCCA 3-FCCNA Fuente: elaboración propia a partir de Collado, A.; Bertuzzi, M. L. (1995) Santa Fe 1880-1940. Cartografia histórica y expansión del trazado. Documento de trabajo $N^{\circ}$ 4, UNL, Santa Fe SISTEMA PROVINCIAL DE ARCHIVOS FOTOGRÁFICOS: www.fotografico. ceride.gov 


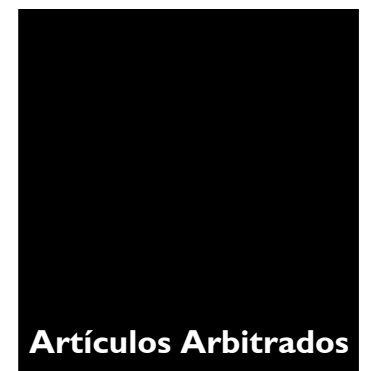

María Alejandra Saus

3- Pertenecía a los ferrocarriles de fomento del Estado y data en la ciudad desde 1908. Su estación definitiva se proyectó y construyó sobre Bv. Gálvez y calle Avellaneda, entre 1912 y 1928. Luego de la nacionalización recibió el nombre de Ferrocarril Nacional General Manuel Belgrano (FCNGMB).

En la década del 90 fueron suprimidos los servicios interurbanos de pasajeros y privatizados los restantes. y privatizados los restantes, quedando activas solo un 20 $\%$ de las vías.

4- La tesis se encuentra en proceso de finalización y aborda las relaciones espaciales y simbólicas entre infraestructura ferroviaria $y$ estructura urbana, tomando como unidades de análisis a las tres estaciones y su entorno inmediato. El título entativo es Ferrocarril y ciudad. Configuración urbana, representaciones sociales y proyectos urbanísticos en torno a la infraestructura ferroviaria. Santa Fe (1885-1989).

5- En principio puerto y ciudad comparten la misma infraestructura; en el siglo XIX esta se autonomiza pero se articula con la ciudad; postearticula con la cindad; posteriormente el urbanismo busca segregar ambos dominios $y$ recientemente se pensará en la refuncionalización de la infraestructura (infraestructura portuaria y ferroviaria pueden asimilarse desde la pueden asimilarse desde
perspectiva urbanistica).
El objetivo del artículo está subordinado a las indagaciones que se vienen realizando en el marco de una tesis doctoral en curso, ${ }^{4}$ que apuntan a caracterizar la configuración urbana en los sectores contiguos a las tres estaciones. Justifica este enfoque el desarrollo de una historia urbana renovada, espacialmente concentrada en la infraestructura ferroviaria. Ello implica un abordaje de tipo microhistórico, que permite afrontar un fragmento urbano y ampliar su escala de observación para develar información inédita. En los términos de la historia social, GiovanNi LeVI (1993) sostiene que se trata de un cambio de escala en las prácticas de investigación, que no implica designar la muestra de una tipología, sino un procedimiento que tiene efectos de conocimiento. Desde esta perspectiva afirmamos que entre infraestructura ferroviaria y ciudad existen reciprocidades que modelan sectores urbanos que, de haberse abordado circunscritos a la ciudad como sistema integral, sus características no habrían sido evidentes. Esto es así porque, según Han Meyer (1999), infraestructura y estructura urbana constituyen dos dominios con fluctuantes relaciones en el tiempo: el dominio técnico del ferrocarril y el dominio social de la ciudad, los que se atraen o repelen en función de los ciclos de uso por los que atraviesa el ferrocarril y de las modalidades urbanísticas que vehiculiza la ciudad para alojar su infraestructura en la trama urbana. ${ }^{5}$

El caso del sector suroeste de Santa Fe se presenta como un objeto interesante para explorar desde el punto de vista del mercado de la tierra urbana. En otro sentido, el FCSF reforzó la renta diferencial de comercio en el área central preexistente y produjo rentas diferenciales de vivienda en los sectores rurales sobre los que se proyectó la expansión urbana. Para arribar a estas reflexiones, estudiamos los tipos de renta urbana en el sentido explicado por SAMUEL JARAMILLO (2008), quien toma como referencia la renta rural sobre la que había trabajado KARL MARX, pero definiendo sus atenuantes para el caso urbano. Por su parte, el FCCNA confirmó la extensión del tejido de la ciudad hacia el norte, sobre una zona de cota elevada, que garantizó una renta diferencial de vivienda de alto interés para el mercado inmobiliario. Ambos ejemplos (a pesar de sus singularidades espaciales y variantes históricas) mantuvieron constante el valor de la tierra y los usos que este fue capaz de inducir. Por el contrario, el borde suroeste de la ciudad, donde se instaló el FCBAyR, estuvo signado por expectativas inmobiliarias fluctuantes.

Históricamente se destacó por ser un fragmento suburbano, con una cota de nivel preocupante frente al riesgo hídrico, si consideramos que se trata de una ciudad en situación geográfica insular (GIORIO, 2009). A la vez, en el siglo XIX estuvo marcado por usos predominantemente rurales, pero, por su proximidad al centro, parecía destinado a ser reservorio de actividades non sanctas que el área central demandaba pero escondía. Ese 
rol se confirmó con la reglamentación del ejercicio de la prostitución, la que movilizó una ordenanza que dejaría a ese sector por fuera de los límites de prohibición, coadyuvando a su marginal caracterización como zona prostibularia. En ese contexto, la instalación del FCBAyR se habría presentado como posibilidad para dinamizar al sector, promoviendo nuevos usos vinculados con el emprendimiento ferroviario y despertando de su letargo al mercado de tierras rurales, que paulatinamente se inclinó hacia la renta urbana diferencial de vivienda (JARAMILLO, 2008). En paralelo, se presentaron proyectos de prolongación de líneas de Tranway por parte de empresarios privados; mientras el Ejecutivo municipal proyectaba la expansión hacia el oeste y autorizaba la ampliación de los límites de la planta urbana. Todas esas acciones apuntaron a ir reconfigurando y ordenando el espacio que se creía sería un área de nueva centralidad.

Avanzado el siglo XX, el énfasis en la industrialización impuesto por un nuevo modelo económico y la urbanización acelerada que propiciaron los sectores excluidos del medio rural fueron haciendo virar esa zona desde su uso residencial y comercial de abastecimiento mínimo hacia la localización de actividades productivas. El proceso fue retroalimentado en 1954, cuando la estación del ex-FCBAyR fue destinada solo al transporte de cargas; decisión que hizo perder al barrio el decoro necesario para el movimiento de pasajeros, ratificando su perfil utilitario. Por su parte, las fincas agrícolas que con la instalación ferroviaria fueron loteadas en pequeñas parcelas urbanas se englobaron en polígonos de actividades industriales, las que son grandes consumidoras de espacio y se ubican en lugares residuales donde las rentas son más bajas. Ahora bien, ¿cómo se produjo esa regresión en la renta urbana del sector, cuando se supone que esta va generalmente en ascenso? ¿Cuáles fueron los catalizadores y atenuantes que desembocaron en el cambio de uso? Trataremos de caracterizar ese proceso a través de diversos indicadores ferroviarios y urbanísticos y por medio del análisis de la evolución del patrón catastral en las manzanas próximas a la estación.

\section{EXPECTATIVAS URBANAS EN TORNO A UNA NUEVA ESTACIÓN FERROVIA- RIA}

El mercado de tierras ante la instalación del FCBAyR

El FCBAyR emprendió la construcción de la estación santafesina en el año 1889. Este ferrocarril se fusionó en 1902 con el Ferrocarril Central Argentino (FCCA), también de capitales británicos (ANDREIS, 2003). Según ScAlabrini OrTiz (2006), se trataba de la compañía extranjera más poderosa e imperialista instalada en Argentina, la que habría cimentado su hegemonía en virtud de una presunta alianza con la oligarquía dirigente, a 
6- Archivo del Concejo Deliberante Municipal. Archivo de Expedientes. Tomo 1889. Folio 558

7- Archivo del Concejo Deliberante Municipal. Archivo de Expedientes. Tomo 1889. Folio 600

8- Archivo del Concejo Deliberante Municipal. Archivo de Expedientes. Tomo 1889. Folio 328 partir de la cual el autor sostiene que le era permitido explotar los recursos del territorio nacional. Por ello, habría operado de forma selectiva en el trazado de sus líneas férreas, abasteciendo con sus servicios a las regiones más prósperas y conduciendo las cargas por una topografía de llanura hacia el Río de la Plata. Al establecer una estación intermedia en la ciudad de Santa Fe, la compañía levantó el edificio de tipo lineal, paralelo a las vías, sobre el ángulo suroeste de la ciudad, en la intersección de las calles Gral. López y Dr. Zavalla, con su fachada dispuesta sobre la primera y orientada hacia el sur, frente a una fracción de chacras.

A diferencia de las estrategias políticas y económicas, tanto de nivel provincial como nacional, que motivaron la instalación del FCSF y FCCNA, respectivamente, el FCBAyR llegó a Santa Fe para satisfacer otros requerimientos. Los documentos consignan que el 16 de noviembre de 1889, la empresa del FCBAyR (luego FCCA) solicitó permiso al Concejo Deliberante para construir su estación ferroviaria en el terreno de la quinta de la familia Cisterna. Anexó al pedido su interés en tierras destinadas a la construcción de dos puentes, uno sobre el río Salado y otro sobre sus bañados, como así también el terreno para el trazado viario. La empresa argumentó que ese ferrocarril significaría un adelanto para la ciudad, y solicitó comprar el terreno de la estación y recibir en donación las tierras de los bañados, de los que no podía obtener ningún beneficio. ${ }^{6}$ La Comisión de Hacienda resolvió que, como el Municipio estaba ligado a contratos tendientes a proveer infraestructura y servicios y las propiedades municipales eran su única fuente de ingresos, no daría gratuitamente esos terrenos al ferrocarril. La compañía aceptó el trato, pero solicitó una rebaja que finalmente se concedió, con la condición de que el trazado ferroviario dejara libre el camino hacia el poblado de Santo Tomé, localizado al suroeste de Santa Fe, cruzando el río Salado?

El agobio financiero del gobierno local tuvo, entre otros antecedentes, una solicitud de autorización para venta de terrenos municipales que efectuó el intendente en 1889, con el fin de afrontar los gastos de instalación de la luz eléctrica. ${ }^{8}$ En ese contexto, la localización del FCBAyR se presentaba como oportunidad para engrosar los recursos municipales, en riesgo por otros compromisos, al tiempo que podía disparar un proceso de urbanización que pudiera activar el mercado de tierras en ese sector. Recordemos que las compañías ferroviarias se mostraron siempre interesadas en generar nueva centralidad. Esto se explica porque para la actividad del intercambio de bienes y servicios hay ciertos lugares a los cuales la convención colectiva les asigna ese uso. La empresa que se ubique en esos sitios puede atraer más clientes e imprimir a su capital mayor velocidad de rotación. Ese 
valor de localización es lo que genera en el espacio urbano una Renta Diferencial de Comercio (JARAMILlo, 2008). Así, la dinámica del centro otorgaba a las compañías una renta diferencial que debían generar expandiendo la urbanización, ya que no siempre era factible la localización tangencial a la ciudad. En ese sentido, las empresas diferenciaron terrenos expropiados, que eran los específicamente destinados a la actividad, y terrenos propios o reservados al negocio inmobiliario en las proximidades de la estación (SANTOS Y GANGES, 2007).

El mecanismo utilizado generalmente en ciudades preexistentes implicaba disponer de una reserva de tierras entre la estación y el núcleo urbanizado, al cual se articulaba aquella por medio de un bulevar. Ese era el eje o columna vertebral que posteriormente estructuraba el loteo de tierra rural entre la estación y la ciudad histórica (SANTOS y GANGES, 2007). Sin embargo, la condición de Santa Fe, ceñida sobre una cuña insular, dejaría las estaciones tangenciales a la planta histórica, con urbanizaciones constreñidas a la disponibilidad de tierras aledañas. JARAMILLO (2008) explica la operación especulativa a partir de la categoría de Renta Absoluta Urbana, que es la base mínima sobre la que se escalonan las rentas diferenciales. Los propietarios de tierras rurales solo las ofrecerán al uso urbano si reciben una renta igual o mayor a la agrícola. La magnitud de la renta rural de las tierras contiguas a la ciudad es el límite mínimo de la tierra urbana. Sin embargo, en el borde de la ciudad se rompe la progresividad de las rentas y se produce un salto, debido a que un terreno urbano debe poseer infraestructura que lo vincule con el resto de la ciudad, y para ello debe intervenir el Estado. Asimismo, factores geográficos, límites normativos a la expansión urbana o propiedades periféricas muy concentradas limitan la disponibilidad de tierras y aumentan su renta.

Por lo expuesto se comprende que las compañías ferroviarias compren terreno rústico al precio que arroja la renta rural, pero paguen al terrateniente original un Precio de Anticipación, es decir, el valor presente del precio futuro (JARAMILLO, 2008), la diferencia a partir de la cual el propietario agrícola incrementa su renta rural y elige vender. Una vez instalada la estación, las empresas venden esa tierra rústica, fraccionada en parcelas urbanas y a un precio que supera ampliamente al de la renta rural. Esta operación va acompañada de servicios e infraestructura garantidos, puesto que el Municipio debe proveerlos hasta la estación para asegurar la accesibilidad al edificio. No obstante, este fue el reverso más amargo para el Municipio de Santa Fe, que en principio había visto incrementados sus ingresos con la venta de terrenos propios al ferrocarril. Como veremos más adelante, el proceso de urbanización no fue tan exitoso como se esperaba, y el gobierno local debió 
9- Archivo del Concejo Deliberante Municipal. Archivo de Expedientes. Tomo 1889. Folio 558

10- El resto pertenecía a la familia Lubary y terrenos municipales destinados a las municipales destinados a las
vías. Plano N. ${ }^{\circ} 11$ Carpeta 5. Archivo de Obras Públicas Municipal. Manzana 1635. Archivo de Catastro.

11- Medidos sobre la copia del Plano N ${ }^{\circ} 11$ Carpeta 5. Archivo de Obras Públicas Municipal.

$\overline{\text { 12- Archivo de Catastro }}$ Municipal. Manzana 1635. Parcela 479.

13- José Maciá pertenecía a la clase política local, integró la Comisión Pro Puerto y fue concejal. igualmente concurrir con el adoquinado y la iluminación. Estas obras debieron realizarse sobre terrenos escasamente ocupados, con insuficientes frentistas con quienes compartir la inversión.

Entre tanto, la compañía del FCBAyR, ahora propietaria de la tierra, recibió el derecho a cobrar una renta urbana solo por tener el dominio jurídico del terreno. Asimismo, recibió Externalidades Positivas, es decir, se benefició del valor de la tierra en forma privada, socializando los costos de producción de la ciudad que debía a sumir el gobierno local (JARAMILLO, 2008). Si bien el Estado cobra impuestos para recuperar esa inversión pública que se desvía al sector privado, es necesario aclarar que las compañías ferroviarias estaban exentas de pagar impuestos y tasas, porque esa fue una de las vías de promoción de su instalación en Argentina. En consecuencia, las compañías compraron tierra bruta, vendieron suelo urbano, cuya plusvalía el Estado contribuyó a incrementar, y mantuvieron la propiedad jurídica de sus inmuebles sin realizar contribución alguna.

En el sector suroeste de Santa Fe - y tal como lo había solicitado al Municipio- el FCBAyR compró la quinta de la familia Cisterna. Según el croquis que adjuntó a la solicitud, requería un área operativa para la estación de $76.913 \mathrm{~m}^{2}{ }^{9}$ De esa área de tres manzanas, dos estaban incluidas en el polígono de la quinta Cisterna ${ }^{10}$ y representaban el sector directamente vinculado con la estación: aproximadamente unos $42.625 \mathrm{~m}^{2}$ (incluyendo futuras calles). ${ }^{11}$ En el año 1891 se realizó la escritura de venta entre los vendedores Apolinario y Sebastián Cisterna y el comprador Alfredo Dickinson, en representación de la Sociedad Dickinson y Compañía. El título se efectuó por un terreno de 271,058 metros de frente, por 300,502 metros de fondo, es decir, 81.453,47 $\mathrm{m}^{2}{ }^{12}$ La diferencia entre esta cifra y lo requerido para la estación representa lo que la empresa se reservó para el negocio inmobiliario, lo que arribaba a $38.828,47 \mathrm{~m}^{2}$. Anteriormente, en el año 1899 , la Sociedad Dickinson y Cía había vendido las dos parcelas en esquina sobre Gral. López y San Juan, es decir, la nueva calle que se había abierto para dar perspectiva al frente de la estación hacia el sur y en clara intención de que esta rematara en el pórtico del edificio. Esa era una modalidad habitual para articular la estación con el centro y luego lotear la tierra intermedia que quedaba como reserva de valor (CLICHEVSKY, 2006); lo curioso es que en vez de orientarse al centro lo hizo a la periferia urbana, o hacia el pueblo de Santo Tomé, que - al parecer - la empresa privilegió por sobre el propio centro de Santa Fe.

En 1901 se oficializó la escritura de venta de Alfredo Dickinson a favor de José Maciá, ${ }^{13}$ quien compró los casi $38.828,47 \mathrm{~m}^{2}$ restantes de terrenos loteados para venderlos individualmente. Entre 1904 y 1909 vendió los de la manzana 1736; entre 1907 y 1921, los de 
Ferrocarril y mercado de tierras. Fugaz expectativa inmobiliaria para el suroeste de la ciudad de Santa Fe (Argentina)
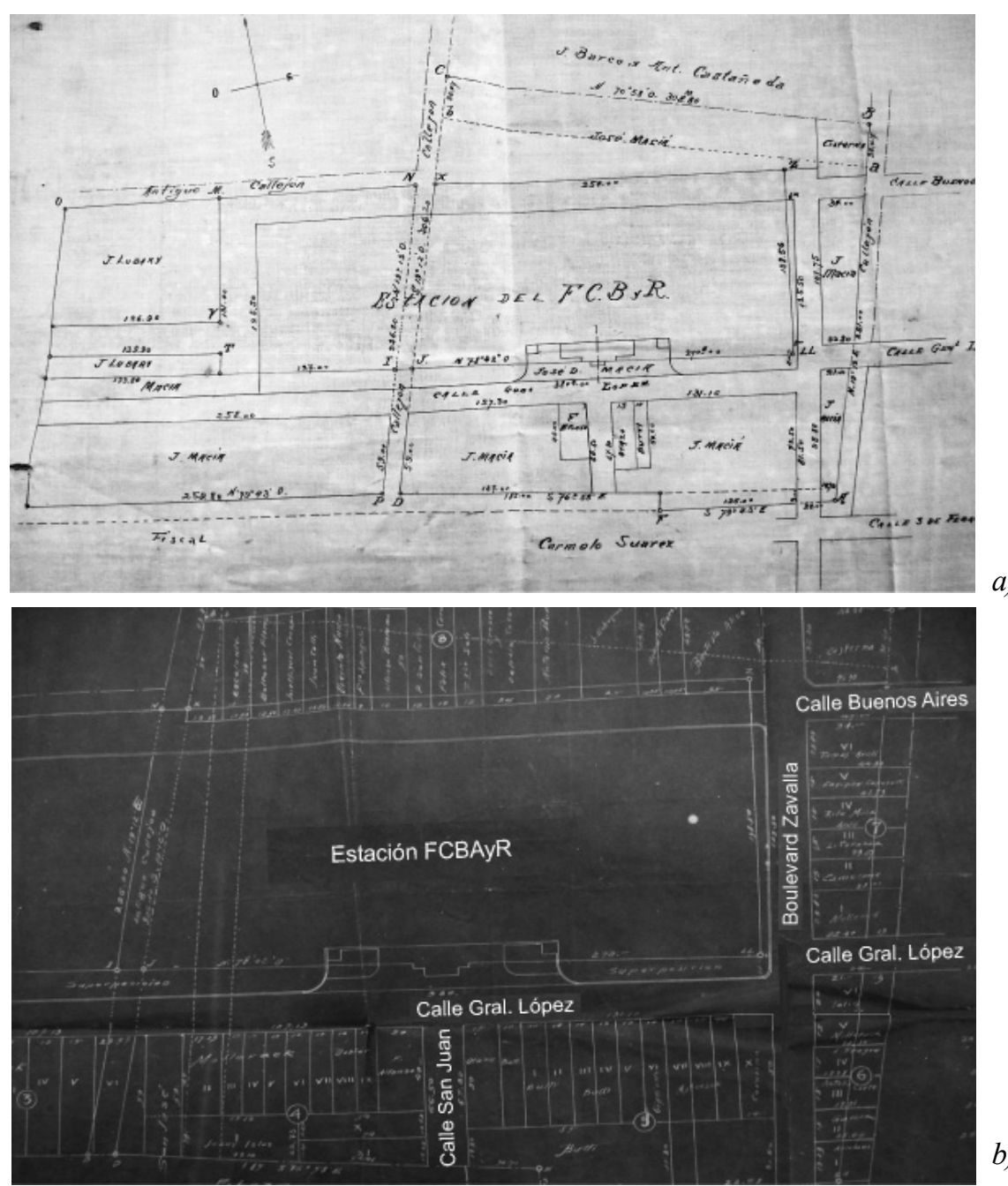

a)

(a y b)- Quinta de Cisterna (polígono $A B C D)$ y parcelamiento vendido por el FCBAyR a José Maciá.

b) Fuente: Archivo de Catastro Municipal. Manzanas 1635 y 1737 
14-Archivo de Catastro Municipal. Manzanas 1736, 1737, 1635, 1536, 1537.

15- Se destaca un bloque de dos plantas y cuatro casas de habitaciones con servicios sanitarios mínimos en cada una y fachada Art Decó, edificio que por sus características podría haber sido un prostíbulo. la 1737 ; entre 1907 y 1913, los de la 1635 ; entre 1904 y 1908, los de la 1536 ; y entre 1908 y 1915 , los de la manzana 1537. Eran variadas las tipologías edilicias que albergaron esas parcelas entre fines del siglo XIX y principios del XX. Sin embargo, predominaba el tejido residencial que se presentó en varios tipos, según los padrones municipales existentes: vivienda unifamiliar de tipo lineal y sucesión de habitaciones, con retiro al frente, galería y patio lateral. Habitualmente se la llama "casa del gringo", y se presentaba como un tipo suburbano, ya que su contraparte urbana poseía vestíbulo, despacho o dormitorio sobre la línea municipal. Por otro lado, se observan habitaciones de inquilinato en tipologías semejantes a la descrita, en tira de dormitorios en planta baja, con sus respectivas cocinas y baños. Otro tipo era una clase de vivienda de mayor jerarquía, sobre las calles principales: Buenos Aires, Dr. Zavalla y Gral. López, de planta más compacta y con ornamentación sobre una fachada sin retiro al frente. En cuanto a los lotes en esquina, aquí es donde aparecían los bloques tipo conventillo, en dos plantas, con dependencias compartidas entre dos habitaciones y salón en planta baja. ${ }^{14}$ Remarcamos que para JARAMILLO la renta de vivienda tiene su valor máximo en áreas centrales, y que el uso reflejado en un sitio de forma predominante es el que arroja la mayor renta. ${ }^{15}$ a)

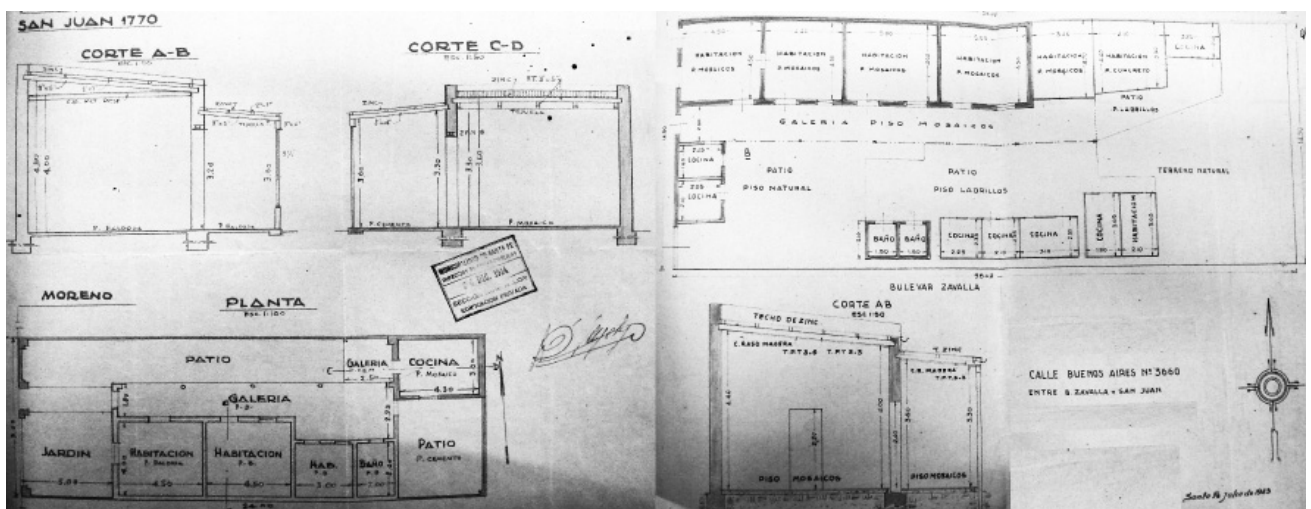


Ferrocarril y mercado de tierras. Fugaz expectativa inmobiliaria para el suroeste de la ciudad de Santa Fe (Argentina)
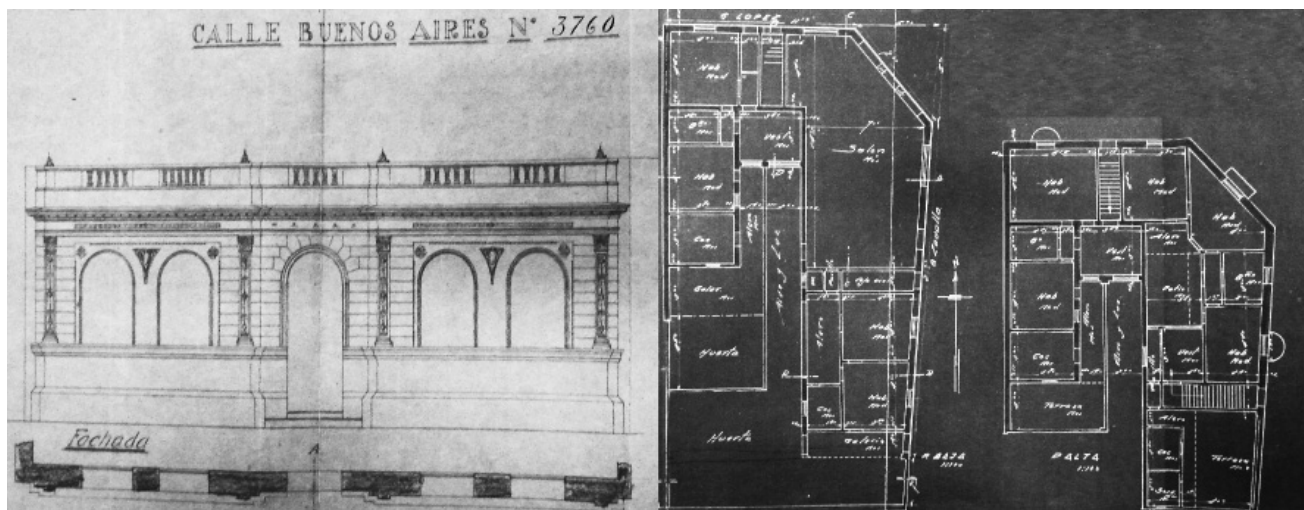

(a y b)- Tipologías residenciales predominantes Fuente: Archivo de Catastro. Manzanas 1736,1737 $1635,1535,1536,1537$

\section{La estación del FCBAyR y el proyecto del intendente Juan Arzeno}

En 1889, el intendente municipal Juan Arzeno se anticipó a la instalación del ferrocarril, sometiendo a consideración del Concejo Deliberante un proyecto urbanístico que contemplaba el trazado de varias avenidas (Collado, 1994). La propuesta no buscó destruir tejido urbano y tenía una vocación expansiva que se instrumentó de la siguiente manera: una serie de avenidas sobre los antiguos caminos territoriales, al norte; la prolongación al oeste del boulevar Gálvez; el trazado de una avenida central; un bulevar sobre la calle Vélez Sarsfield, al este; y otro sobre la calle Dr. Zavalla, al oeste, sobre la cual se localizaría la estación. La propuesta fue autorizada por Ordenanza Municipal, pero su ejecución quedó sin efecto: “.... El Señor Intendente queda autorizado para trazar otro Boulevard de Norte á Sud por la calle Dr. Zavalla, que arrancando de frente al terreno en que se hará la Estación del Ferro Carril á Sunchales [FCBAyR] se prolongue hacia el Norte hasta dar con el Boulevard Gálvez; este Boulevard se denominará 'Gobernador Zavalla'...". ${ }^{16}$ En este último caso, podría tratarse de un intento de emular una operación inmobiliaria que había sido exitosa, congregando en el año 1887 a las instalaciones del FCSF, con el trazado del boulevar Gálvez y el loteo de barrio Candioti. ${ }^{17}$

Recordemos que, a diferencia del caso europeo, donde los bulevares se trazaban cercenando el tejido existente, en estas latitudes se planeaban para la promoción inmobiliaria en tierras no urbanizadas pero próximas a la ciudad. El inconveniente en el suroeste de Santa Fe, a diferencia del caso del barrio Candioti, era que los terrenos ocupaban un área

16- Archivo del Concejo Deliberante Municipal. Archivo de Expedientes. Tomo 1889. Folio 218 .

17- Propuesta de urbanización 17-Propuesta de urbanizacion
presentada por Emilio Schnopresentada por Emilio Schno-
or, ingeniero perteneciente a la empresa constructora del FCSF. El proyecto incluía como variables para la expansión de la ciudad la urbanización de un sector de chacras chacras de considerable extensión, pertenecientes a dos propietarios, y comprendía el trazado de un bulevar, de orientación este-oeste, por el cual pasaría un tranvía. Archivo del Concejo Deliberante Municipal. cejo Deliberante Municipal. Archivo de Expedientes.
1887-1888. Folio 219. 


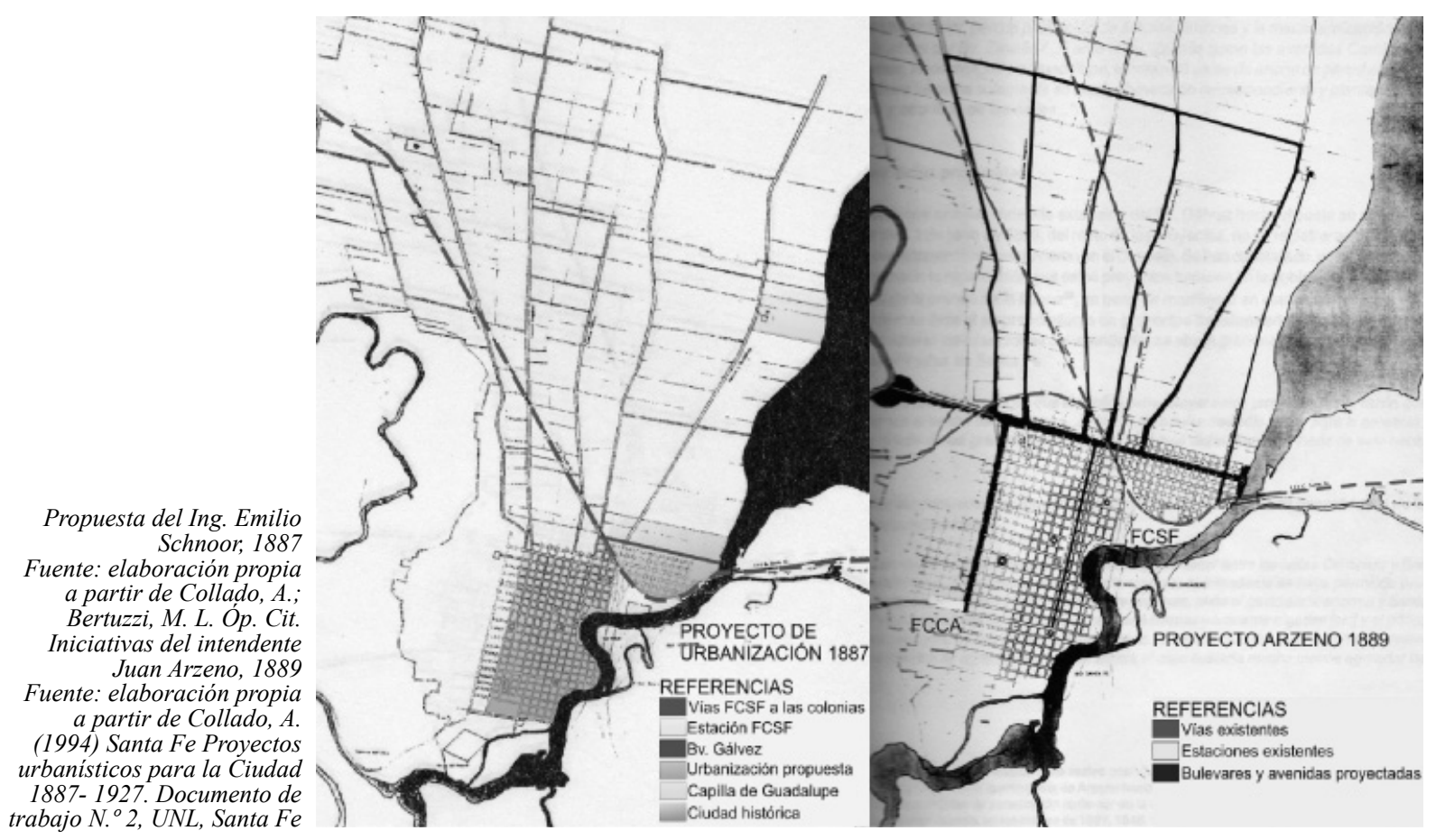

ostensiblemente deprimida y dieron muestra en diversas oportunidades de su posibilidad de anegamiento. Fundamentalmente, la inundación de 1905 había dejado a la estación ferroviaria y al sector oeste casi completamente anegados. La consecuencia más notoria es que las áreas de riesgo se constituyen en potenciales reservorios de tierra para sectores marginados, puesto que no despiertan interés para el mercado formal. Según NorA Clichevsky (2006), una inundación afecta al mercado de tierras y puede producir la paralización de alguno de los submercados o una baja en los precios de los terrenos. "El mercado legal de tierras ha podido funcionar, y aún lo hace, con escasas regulaciones. Dado que los precios se hallan definidos, entre otros elementos, por la calidad del suelo, las áreas inundables son las de menor precio y, por lo tanto, las que puede comprar la 
Ferrocarril y mercado de tierras. Fugaz expectativa inmobiliaria para el suroeste de la ciudad de Santa Fe (Argentina) población de menores ingresos. Y aquellos que no pueden acceder al mercado legal, lo hacen al mercado informal (sin ningún control sobre la aptitud de las tierras) u ocupan tierras fiscales o privadas en los peores lugares desde el punto de vista ambiental (por lo tanto con un alto riesgo de inundabilidad)..." (CLICHEVSKY, 2006: 46).

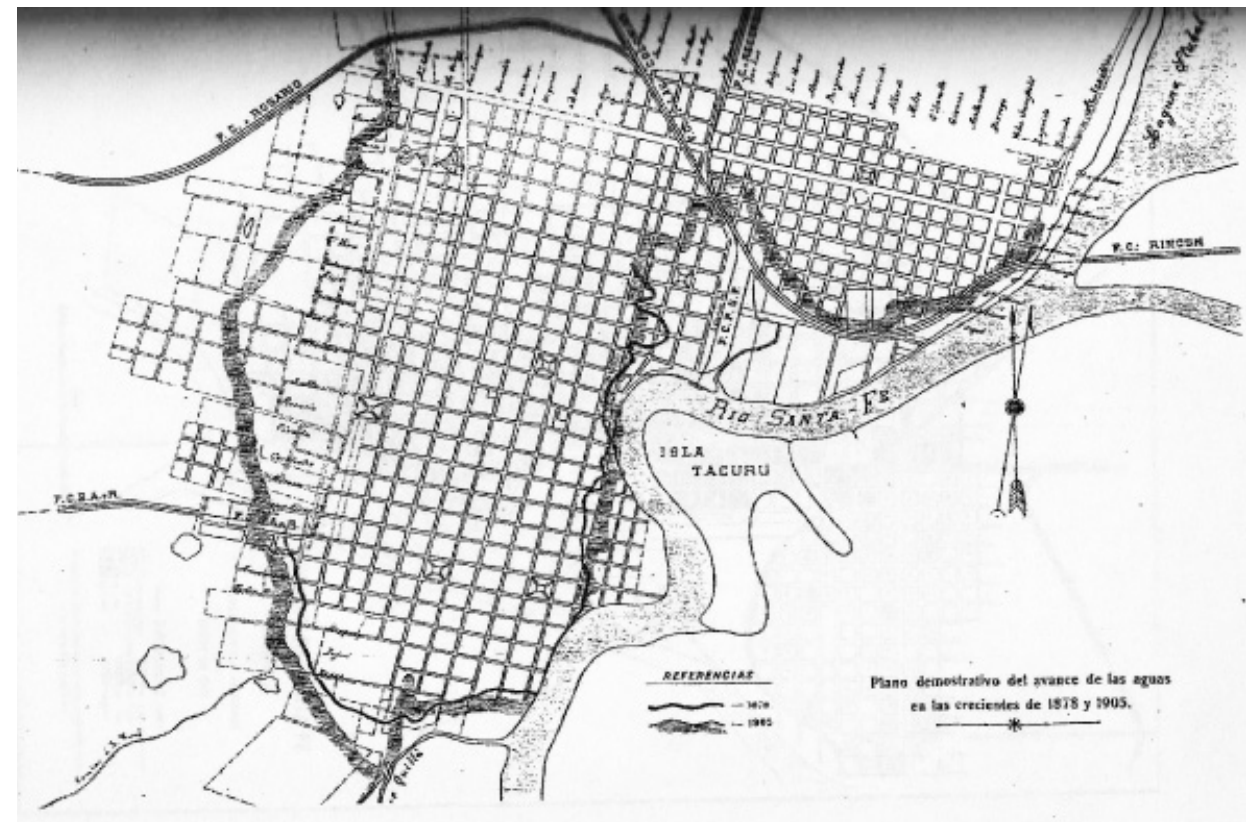

Contrariamente, la zona de Candioti era la de mayor altitud de la ciudad, con un cota de $104.61 \mathrm{~m}$ en su punto más alto. Como referencia, basta mencionar que en aquel momento el nivel de los rieles del ferrocarril sobre el muelle del puerto era de $100 \mathrm{~m}^{18}$ Por otra parte, el prestigio que adquirían en esa época los terrenos altos no se sustentaba solo en su imposibilidad de anegamiento, sino que debe leerse bajo la influencia del Higienismo. Esta disciplina articulaba la disponibilidad de terrenos elevados con la salubridad de la ciudad, en tanto las epidemias se vinculaban con el medio ambiente, y cuanto más ven-
18- Archivo del Concejo Deliberante Municipal. Archivo de Expedientes. Tomo 1889. Folio 454.
"Plano demostrativo del avance de las aguas en las crecientes de 1878 y 1905 Fuente; Collado, A.; Bertuzzi. M. L. Op. Cit. 
19- El Orden, viernes 1 de noviembre de 1929. Pág. 15. tilados y asoleados estuvieran los predios, parecían ser más saludables. Esta apreciación repercutía negativamente en la magnitud de la renta en esas tierras, a las que la convención colectiva les asignaba un uso y un precio acorde con la renta que arrojaran. Reforcemos la comparación con barrio Candioti a partir de un ejemplo. Un aviso de la inmobiliaria "La Gestionadora Comercial", publicado en el diario El Orden en 1929, ofrecía una vivienda de dos habitaciones y dependencias, en un lote de $390 \mathrm{~m}^{2}$. La propiedad estaba ubicada sobre calle Dr. Zavalla casi Entre Ríos, a cuatro cuadras de la estación del FCCA (ex FCBAyR) y su precio era de \$8.500. En la misma lista, se vendía una vivienda de idénticas características, en un solar de $223.3 \mathrm{~m}^{2}$, ubicado en calle Ituzaingó casi Mitre a once cuadras al este de la estación del FCSF, y su valor era de \$15.000. Como se ve, ambas viviendas compartían la misma cantidad de locales; se encontraban sobre vías de circulación relevantes y ocupaban áreas de reciente formación. Asimismo, la del sector sur tenía mayor superficie y estaba más próxima a la estación. Sin embargo, el precio de la propiedad situada en barrio Candioti era prácticamente el doble. ${ }^{19}$

Volviendo al proyecto de bulevares que presentó Juan Arzeno y a su posible interés en expandir la planta urbana hacia el oeste, podemos especular dos intenciones. Evidentemente la localización de la estación cambió las variables a partir de las cuales se podía pensar en la activación del mercado de tierras en el sector. Si la intención del intendente fue imitar la operación inmobiliaria efectuada al este, el anegamiento del suroeste en 1905 demostraría que por más que el Estado habilite tierras para la urbanización, no es suficiente que las normas autoricen un uso en un lugar determinado para que el uso se haga presente, es la estructura del mercado la que lo hace posible (JARAMILLO, 2008). Si la iniciativa no despierta interés para el mercado formal de tierras, la estación cargará con la responsabilidad de activar usos secundarios dependientes de la actividad ferroviaria. ¿Qué usos? Los que define el sistema de precios de la tierra, afectados por la construcción colectiva de una carga semántica negativa que asigna a esa sección un rol prostibulario, y por la evidencia de la inundación de 1905. Ahora bien, cabe la posibilidad de que la intención de Arzeno haya sido "habilitar" un mercado informal de tierras, permitiendo el loteo de terrenos inundables. En ese orden, el Estado habría aceptado la ocupación de tierras de escaso valor comercial y malas condiciones físico- ambientales, al mismo tiempo que habría protegido la propiedad privada en un sinnúmero de terrenos que aún restaban ocuparse (CLICHEVSKY, 2006). Si esto fue así, Arzeno habría actuado de manera funcional al mercado, habilitando una reserva de tierras para personas de bajos recursos que quedarían excluidas del acceso a los sectores jerarquizados. Ante estas circunstancias, la localización de la estación quedaba casi como una anécdota, un artefacto que movilizó el mercado de tierras en su entorno inmediato y por iniciativa de la compañía, pero que no fue capaz de 
Ferrocarril y mercado de tierras. Fugaz expectativa inmobiliaria para el suroeste de la ciudad de Santa Fe (Argentina) propagar su efecto al mercado formal.

Las iniciativas de los empresarios y las limitaciones del Municipio

El 22 de octubre de 1889 la Empresa del Tramway Ciudad de Santa Fe presentó una nota al intendente. Explicaba que la compañía había obtenido el 11 de mayo de 1889 la concesión para la construcción de un tranvía que por la calle 3 de Febrero se dirigiera hasta la que fuera la quinta de Cisterna, donde iba a construirse la estación del ferrocarril. Argumentaban que la línea del Tramway debía correr por calles que aún estaban sin abrir, que las obras de la estación no habían dado comienzo y que tardarían mucho en hacerlo. Sobre la base de ese escenario pidieron una prórroga de ocho meses en la concesión, la que sintetizaban del siguiente modo: "En esta virtud y, considerando que no existe objeto alguno en llevar el Tramway á un paraje despoblado, no conociendo además la ubicación precisa de la proyectada Estación, á lo cual se añade las calles sin abrir, por estas razones solicito del Sr. Intendente se sirva prorrogar por ocho meses más el plazo fijado por el contrato de 11 de Mayo del corriente año para dar comienzo á las obras del ramal de esta Empresa, en cuyo lapso de tiempo es de esperar hayan desaparecido las causas enumeradas que dificultan en la actualidad su construcción", 20

Prosiguiendo con las expectativas movilizadas por la localización de la estación, el 23 de octubre de 1889 se efectivizó otra propuesta de Tramway, que partiendo de Santa Fe cruzaba el río Salado hacia el pueblo de Santo Tomé. Los empresarios proyectaron un coche y trocha de similares características al de la Empresa Ciudad de Santa Fe, proponiendo acceder directamente al ferrocarril, según un plano que adjuntaron especificando el recorrido y solicitando que el gobierno se encargase del adoquinado. Esta oferta, conjuntamente con la ya descrita, se anticipó a las obras del ferrocarril y propuso unir la futura estación con Santo Tomé, mientras la otra lo hacía con el centro de la ciudad. Es evidente que la noticia de la instalación del FCBAyR había creado amplio interés empresarial, pero tropezaba con un entorno prácticamente despoblado, como puede comprobarse en la cartografía histórica (COLLADO-BERTUZzi, 1995). En este sentido, la iniciativa privada se adelantaba incluso a la apertura de las calles por las que debía circular el tranvía, lo que requería la intervención pública.

La urbanización del flanco este de la estación ferroviaria era solo una incipiente realidad hacia 1892, cuando el servicio fue librado al uso público. El 25 de octubre de ese mismo año, Florentino Martín, gerente de la empresa del Tramway Progreso de Santa Fe a quien el gobierno había mandado construir un tranvía desde el sureste hacia el FCBAyR, también
20- Archivo del Concejo Deliberante Municipal. Archivo de Expedientes. Tomo 1889. Folio 521 . 
21- Archivo del Concejo Deliberante Municipal. Archivo de Expedientes. Tomo 1892. Folio 484.

22- Archivo del Concejo Deliberante Municipal. Archivo de Expedientes. Tomo 1892. Folio 34.

23- Ciudad de Santa Fe. Plano del Censo Municipal, año 1901 (fotografia). Departamento de Estudios Etnográficos y Coloniales. solicitó una prórroga para la ejecución de los trabajos. Ese tranvía debía partir de la calle 9 de Julio y dirigirse a la estación, pero la calle Buenos Aires estaba cerrada por terrenos particulares que el Municipio debía expropiar para poder abrir dicha vía de circulación hacia el oeste hasta la calle Dr. Zavalla. Ese fenómeno naturalmente impedía los trabajos de la empresa, que debieron ser postergados. ${ }^{21}$ En rigor, la apertura de calles estaba siendo una demanda que el Concejo Deliberante intentó formalizar cuando el 20 de enero de 1892 presentó un proyecto de ordenanza, en el cual se declaraba planta urbana al área comprendida entre Bv. Gálvez, al norte; el arroyo Quillá, al sur; el río Santa Fe y la laguna Guadalupe, al este; y el río Salado, al oeste. Por consiguiente, el intendente quedaba autorizado para abrir calles en toda la planta y prolongar los bulevares; así también como para crear fondos públicos tendientes a indemnizar a los propietarios damnificados. ${ }^{22}$

La intención de urbanizar el sector aledaño a la estación se tornaba incompatible con las posibilidades económicas del Municipio. Tanto es así que el 4 de agosto de 1892 un proyecto de ordenanza derogó los estatutos de 1888 y 1892, por medio de los cuales se había suspendido la venta de tierras municipales. Paulatinamente, se verifica que la oportunidad que tuvo el gobierno de vender terrenos propios a la compañía del FCBAyR presentaba un revés que se había tornado una carga. Esto fue así porque en un breve lapso el Ejecutivo se encontró ante el compromiso de urbanizar un sector que hasta hacía tres años era marcadamente suburbano. Por ello, una importante cantidad de solicitudes de infraestructura tendrían como telón de fondo al FCBAyR que se constituía en el límite de las obras para ejecutar. El Municipio debía garantizar la accesibilidad y la iluminación hasta los ingresos a la estación, pero la baja densidad de ocupación de las manzanas que lindaban con Gral. López impedía suponer que los contribuyentes frentistas financiarían las obras, como había ocurrido en sectores céntricos. De hecho el Censo Municipal del año $1901^{23}$ evidencia que las manzanas del frente sur de Gral. López, desde la calle 4 de Enero hacia el oeste, hasta Dr. Zavalla, contaban con 148, 45, 52, 45 y 24 habitantes, respectivamente, cuando frente a la estación del FCSF la manzana sur ya estaba ocupada por 187 almas. Debemos recalcar que el precio de la tierra disminuye donde el promotor debe proveer infraestructura, un compromiso que en el suroeste evadían públicos y privados.

\section{Representaciones que revelan expectativas incumplidas}

Para calibrar desde el imaginario urbano este accidentado proceso de renovación del sector, nos valdremos de la percepción que emana de la opinión pública. El sentido en que abordamos la prensa local remite a su mérito de vehiculizar los hechos y sus representaciones, o la valoración que la clase representada en la prensa hace de aquellos (PONTE, 1999). Desde el punto de vista periodístico, el tratamiento de los asuntos del FCCA siempre 
Ferrocarril y mercado de tierras. Fugaz expectativa inmobiliaria para el suroeste de la ciudad de Santa Fe (Argentina) fue notablemente escaso, aun a pesar de la importancia de esa compañía ferroviaria en el país. Sin embargo, esa visible omisión no deja de ser reveladora. Lo que subyace es que el FCCA tenía una existencia marginal para la opinión pública, porque los asuntos que giraban en torno a esa compañía ferroviaria no implican factores de progreso a nivel urbano. En principio, resaltamos el valor estratégico que poseía para los sectores hegemónicos santafesinos la convergencia de cargas efectivas o potenciales hacia al puerto local, en tanto era ese estrato social representado en la prensa el que se apropiaba de su renta. Esa función era de carácter secundario en el caso de las cargas transportadas por el FCCA, ya que este concentraba su accionar en los puertos de Rosario y Buenos Aires.

Para establecer una comparación con las otras estaciones, subrayamos que el FCSF poseía una estación terminal en la ciudad y podía asegurar la salida de las cargas del noroeste provincial a través del puerto local. El FCCNA también gozaba de estación terminal y permitía exportar por Santa Fe las materias primas de gran parte del territorio nacional y países limítrofes. El FCCA no poseía una estación terminal, y a principios del siglo XX se utilizaba mayormente para pasajeros, motivo por el cual su incidencia en el puerto local era secundaria. Asimismo, el diario El Orden planteó una crítica al FCCA en un sentido urbanístico. A la estación le cuestionaba su abandono y la calificó de indecente para la segunda provincia del país. En cuanto al sector que ocupa, este era caracterizado como una zona sitiada por los burdeles. En ese orden, tal como lo explica PonTE (1999), la ciudad del siglo XIX tenía en la prostitución una afanosa demanda y una problemática que ameritó reglamentación. Como consecuencia, el reglamento llegó a los prostíbulos santafesinos y no solo dispuso normas de sanidad para las meretrices y su ámbito de trabajo, sino que estableció una zonificación que dejara a las casas de tolerancia por fuera del área central de la ciudad, a fin de que los niños y las "mujeres decentes" no pudieran verlas. La Ordenanza 1526 de 1915 delimitó la zona prohibida para el ejercicio de la prostitución entre las calles: Bv. Pellegrini, al norte; J. J. Paso, al sur; San Lorenzo, al oeste; y el río, al este, quedando liberado el sector suroeste. ${ }^{24}$

Pero si volvemos a ceñirnos al área que afecta directamente a la estación, diversas crónicas daban cuenta de un sitio degradado y de escasa movilidad en el mercado de tierras. Si bien el ferrocarril se constituía en una oportunidad para dinamizar la zona, fue habitual el reconocimiento de un proceso inverso: el sector terminaba devaluando al ferrocarril, según las autoridades de la compañía. Por su parte, El Litoral sostenía que la estación era un edificio ruinoso que rebajaba la importancia del Municipio. El mal estado de mantenimiento y las incomodidades funcionales se exhibían como elementos que impedían el progreso del barrio. Dos meses más tarde de esa crónica, el mismo diario publicó el compromiso
24- "El radio de las casas de toleran (sic) es por demás de inconveniente. Los ediles deben considerar el asunto". $E$ Orden jueves 24 denoviembre Orden, jueves 24 de noviembre
de 1927 . Pág. 6 . 
25- "LA ESTACIÓN DEL CENTRAL ARGENTINO SERÁ PUESTA EN CÓMODAS CONDICIONES. No estaria fuera de lugar que también se tuviese en cuenta el aspecto exterior $y$ el interior". El Litoral, viernes 12 de rior". El Litoral, viernes 12 de
marzo de 1937. Pág. 3.

26- "LA ESTACIÓN DEL FC CENTRAL ARGENTINO”. El Litoral, domingo 24 de octubre de 1937. Pág. 3 . de la empresa en el arreglo del edificio, mientras la compañía se disculpaba diciendo que la estación no tenía mantenimiento porque el barrio no mostraba progresos. ${ }^{25}$ Siete meses después los periodistas verificaron que no hubo acciones y retomaron la crítica: "El viejo caserón es de un aspecto interno y externo deplorable. Numerosas estaciones de escasa actividad y levantadas en lugares donde se carece de pavimento duro, ofrecen mejor vista que la local de referencia. No se explica la desatención de dicho F. C. hacia los intereses santafesinos; esa falta de colaboración al progreso de la ciudad es impropio de la antigua compañia a quien el comercio, la industria y la sociedad en general de Santa Fe, favorece sin duda. Ya debió la compañía levantar un buen edificio que embelleciese el barrio sudoeste; aún en la época de más intensa crisis, la línea del C. Argentino a esta capital ha trabajado en forma relativamente satisfactoria". ${ }^{26}$

Trayectoria descendente de la renta y cambio de usos ferroviarios y urbanos

Así como a fines del siglo XIX la instalación de la estación aparecía como medio para dinamizar al sector, en sentido inverso en la década del 30 el deterioro del edificio fue un argumento que explicaba la falta de progresos del barrio, y en ese sentido la opinión pública pidió su renovación. Por su parte, en la década del 40 se produjo la nacionalización de los ferrocarriles de capitales extranjeros, realizándose el acto de toma de posesión de los ferrocarriles británicos en Buenos Aires el 1..$^{\circ}$ de marzo de 1948. Ese suceso instauró una nueva etapa en la historia de tensiones entre intereses ferroviarios y urbanos. Como consecuencia de las nuevas políticas, en 1954 se oficializó en Santa Fe la estación única de pasajeros en el edificio del ex-FCCNA, rebautizado como Ferrocarril Nacional General Manuel Belgrano (FCNGMB), el que absorbió las actividades del FCSF; mientras la estación del FCCA, luego Ferrocarril Nacional General Bartolomé Mitre (FCNGBM), quedó destinada exclusivamente para el movimiento de mercancías.

Desde el punto de vista urbanístico ello significa un cambio en el tipo de actividades que atraiga una estación a su entorno. Así, si el edificio se especializa en el servicio de pasajeros, es factible que propicie el establecimiento de actividades terciarias y residenciales; si en cambio está reservado solo para el transporte de cargas, puede atraer usos industriales o productivos (SANTOS y GANGES, 2007). Basta revisar el concierto de instalaciones productivas que se congregaron frente a las naves de la estación Santa Fe del FCNGBM (relegado a las cargas durante años) para comprender la localización de esos usos en el suroeste. Entre esas instalaciones destacamos diversos frigoríficos; una procesadora de viñedos, bodegas y olivares; una planta elaboradora de licores y refrescos; etc. 
Ferrocarril y mercado de tierras. Fugaz expectativa inmobiliaria para el suroeste de la ciudad de Santa Fe (Argentina)

El cambio del uso residencial al industrial fue especialmente notorio en las manzanas 1736 y 1737, y no solo se reflejó en los 40 debido a la instauración de un nuevo modelo económico que sustituyó importaciones, y cuyas instalaciones productivas terminaron atrayendo un ferrocarril que había quedado destinado solo a cargas. Para que dichos usos, que son grandes consumidores de espacio, se localicen allí, la zona debe generar rentas urbanas más bajas. Así, se puede prescindir de la concurrencia de público que le es propia al centro y de la directa relación entre consumidores y comerciantes que requieren las actividades de intercambio. La industria tiende espontáneamente a ubicarse en los lugares residuales donde las rentas disminuyen. Por ello, la variación en el uso de un área urbana implica que el ordenamiento de las rentas potenciales secundarias se transformó (JARAMILLO, 2008). Citamos como ejemplo al frigorífico avícola "La Estrella", que fue el primero en englobar seis parcelas de la manzana 1736, antes destinadas mayormente a vivienda, adquiriendo las primeras cuatro entre enero, mayo y noviembre de 1944 y la otra en abril de $1945 .{ }^{27}$

La operación se realizó antes de la nacionalización ferroviaria (por la cual ese ferrocarril quedó relegado a cargas) y demuestra que ya en el $40 \mathrm{y}$, a pesar de sus iniciales aspiraciones de convertirse en un nuevo centro, el sector suroeste era un borde degradado. Lógicas específicamente urbanísticas (el carácter suburbano del sector, la baja cota de nivel del suelo o las limitaciones económicas del Municipio) y otras propiamente ferroviarias (el escaso interés que esa compañía puso en Santa $\mathrm{Fe}$, el tipo del edificio orientado al sur, el posterior deterioro y su final destino para cargas) se combinaron para que ese espacio no pudiese superar su condición inicial de periferia marginada.
27- Archivo de Catastro Municipal. Manzana 1736 (a y b)- Cambios de uso (Frigorifico "La Estrella") y configuración actual del sitio

Fuente: Archivo de Catastro. Manzanas 1736 y 1737

Fotografias: registro propio

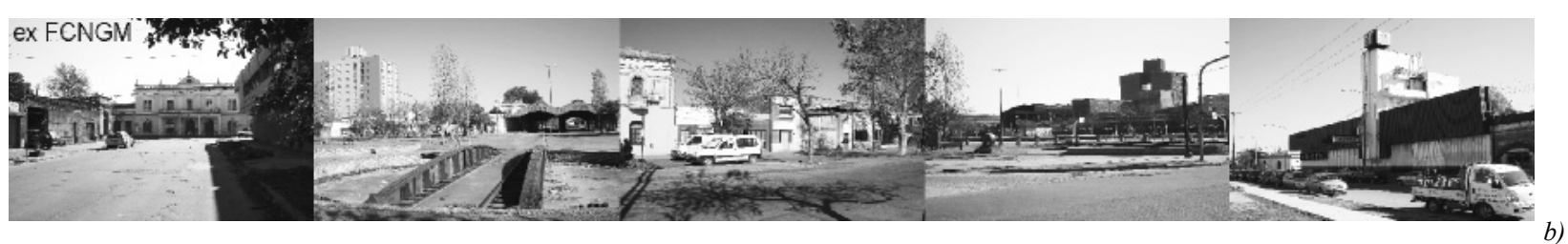




\section{BIBLIOGRAFÍA}

"Antropología y Microhistoria: conversación con Giovanni Levi" (1993) En: Manuscrits, N. ${ }^{o}$ 1. págs. $15-28$. En línea < http://ddd.uab.cat/pub/manuscrits/02132397n11p15.pdf> ANDREIS, Andrés (2003) El ferrocarril. Lo que el tiempo no borró. Secretaría de Extensión, Universidad Nacional del Litoral, Santa Fe.

CLICHEVSKY, Nora (2006). "Estado, mercado de tierra urbana e inundaciones en ciudades argentinas". En: Cuadernos de Geografia 15. Departamento de Geografía, Universidad Nacional de Colombia, Bogotá.

COLLADO, A.; BERTUZZI, M. L. (1995) Santa Fe 1880-1940. Cartografía histórica y expansión del trazado. Documento de trabajo N. ${ }^{\circ}$ 4, UNL, Santa Fe.

GIORIO, Blanca (2009) La construcción del espacio geográfico de la ciudad de Santa $\mathrm{Fe}$, 1573-2007. Ministerio de Innovación y Cultura. Gobierno de Santa Fe, Santa Fe.

JARAMILLO GONZÁLEZ, Samuel (2008) Hacia una teoría de la renta del suelo urbano. Segunda edición revisada y aumentada. Ediciones Uniandes, Bogotá.

MEYER, Han (1999) City and Port. Transformation of Port Cities. London, Barcelona, New York, Rotterdam. International Books, Rotterdam.

PONTE, Jorge Ricardo (1999) La fragilidad de la memoria. Representaciones, prensa y poder de una ciudad latinoamericana en tiempos del modernismo. Mendoza, 1885/1910. Fundación CRICYT, Mendoza.

SANTOS Y GANGES, Luis (2007) Urbanismo y ferrocarril. La construcción del espacio ferroviario en las ciudades medias españolas. Fundación de los Ferrocarriles Españoles, Madrid.

SCALABRINI ORTIZ, Raúl 1940 (2006) Historia de los Ferrocarriles Argentinos. Lancelot, Buenos Aires. 